
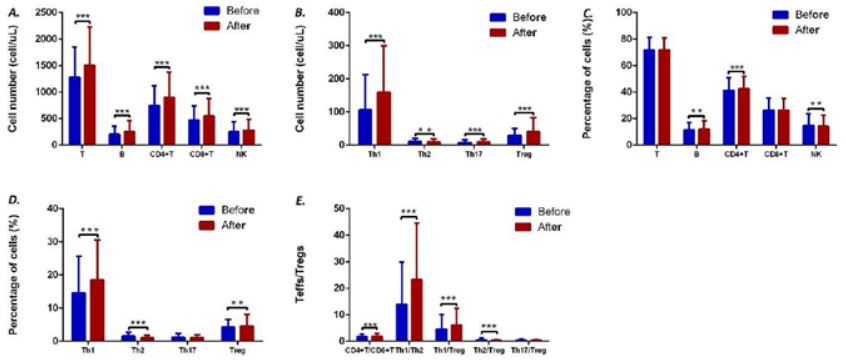

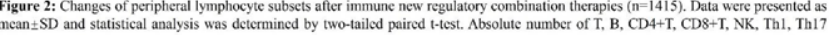
and Tregs were significantly increased ( $A$ and B). The proportion of B, Thl, CD4-T and Tregs were also increased ( $\mathrm{C}$ and D), while the ratio of Teffs $T$ Tregs such as Th2 Tregs
${ }^{*} \mathrm{P}<0.05, * * \mathrm{P}<0.01, * * * \mathrm{P}<0.001$

Acknowledgments: None.

Disclosure of Interests: None declared

DOI: 10.1136/annrheumdis-2020-eular.2138

\section{AB0347 INCREASING TO OPTIMAL METHOTREXATE DOSE MIGHT BE A BETTER TRADITIONAL DMARD STRATEGY IN RA TREATMENTS: A RANDOMIZED CASE-CONTROL TRIAL OF HAKKA PEOPLE IN SOUTHERN CHINA}

D. Lin' ${ }^{1}$, Y. Wen ${ }^{2}$, Y. Zhang ${ }^{1}$, Q. Chen ${ }^{2}$, Y. Pan ${ }^{1}$, L. Qing ${ }^{1}$, J. Gu'. ${ }^{1}$ the $3 r d$ Affiliated Hospital of Sun Yat-sen University, Guangzhou, China; ${ }^{2}$ The $3 r d$ Affiliated Hospital of Sun Yat-sen University Yuedong Hospital, Meizhou, China

Background: The optimal methotrexate (MTX) dose is defined as $0.3 \mathrm{mg} / \mathrm{kg} / \mathrm{week}$ or $\geq 20 \mathrm{mg} /$ week at 6 months. [1] Considering average weight of Chinese, [2] the optimal MTX should be $>15 \mathrm{mg} / \mathrm{w}$. However, not more than $30 \%$ in 25191 RA cases ever had MTX treatment in CREDIT (Chinese Registry of Rheumatoid arthritis). [3] The biggest concern is side effects of MTX. Our study is to investigate whether increasing MTX would get better results accompanied with more side effects to Chinese people. Objectives: Hakka people have the purest genes of the majority people-Han in China. It is planned to recruit 160 RA patients in Meizhou, where is a gathering place of Hakka people.

Methods: The RA volunteers had no relief with $10 \mathrm{mg} / \mathrm{w}$ oral dose of MTX with/ without other 1-2 inadequate dose of DMARDs for at least 3 months. They were randomly divided into 1:1 groups*. The experimental group would be treated with original DMARDs and incremental MTX (gradually increased to the optimal oral dose $(0.3 \mathrm{mg} / \mathrm{k} / \mathrm{w})$ in the first 12 weeks and folic acid (the dose adjusted on demand with range from $5 \mathrm{mg} / \mathrm{w}$ to $5 \mathrm{mg}$ tid). While the control group would be treated with original MTX dose $(10 \mathrm{mg} / \mathrm{w}$ ) but incremental original DMARDs(gradually increased to the maximum dose in the first 12 weeks). The two groups would keep the treatment at $12^{\text {th }}$ week last to the $36^{\text {th }}$ week, and the efficacy and safety indexes would be evaluated during the whole study.

Results: 1)We planned to recruit 160 RA patients in our study. 46 Hakka RA patients were enrolled in the study so far. 2 of 46 finished the $24^{\text {th }}$ week visit and 24 finished the $36^{\text {th }}$ week visit. The average age is $54.2 \pm 9.3$ years old, the average weight is $59.1 \pm 11.1 \mathrm{~kg}$, and the female to male ratio is $41: 5$.

2)The average Folic acid dose is $14.4 \pm 9.5 \mathrm{mg} / \mathrm{w}$ in the experimental group at the $12^{\text {th }}$ week.

3)The morning stiffness time, PGA, PhGA, HAQ, DAS28 were better in experimental group after 12 weeks though slightly worse during $0-12$ weeks. $100 \%(12)$ patients in experimental group, while $66.67 \%(8 / 12)$ in control group reach ACR20. 4) Only 1 case $(5.9 \%, 1 / 23)$ had adverse event while 6 cases $(26 \%, 6 / 23)$ occurred adverse events. All events were mild level. 1 case $(4.2 \%, 1 / 23)$ in control group withdrew from the study because the disease was getting worse during 0-24 weeks. Conclusion: Hakka patients in China might have better outcomes due to increasing MTX to the $0.3 \mathrm{mg} / \mathrm{kg} / \mathrm{w}$ dose than increasing the other DMARDs. Therefore, We recommended the Chinses patients choose MTX as first incremental DMARD. The appropriate dose of Folic acid plus with the optimal dose of MTX in our study is higher than previous studies (such as $13.0 \pm 4.8 \mathrm{mg} / \mathrm{w}$ reported by Gaujoux-Viala, 2018[1]). We recommended Chinese patients take $15 \mathrm{mg} / \mathrm{w}$ folic acid to prevent MTX side effects in view of lower folic acid level in Chinese population.[3]

References:

[1] Gaujoux-Viala C, Rincheval N, Dougados M, et al. Optimal methotrexate dose is associated with better clinical outcomes than non-optimal dose in daily practice: results from the ESPOIR early arthritis cohort. Ann Rheum Dis. 2017 Dec;76(12):2054-2060.

[2] Nan Jiang, Mengtao Li, Yanhong Wang, et al. Baseline characteristics and treatments among patients with rheumatoid arthritis: the CREDIT study in China, 2016-2018. Ann Rheum Dis. 2019 Jun; 78 (Suppl 2) 1404-1405.
[3] He Y, Pan A, Hu FB,et al. Folic acid supplementation, birth defects, and adverse pregnancy outcomes in Chinese women: a population-based mega-cohort study, Lancet, 2016 Oct,Volume 388, Number 1, pp. S91-S91-(1)

Disclosure of Interests: None declared

DOI: 10.1136/annrheumdis-2020-eular.2709

\section{AB0348 THE EFFECTIVENESS AND SAFETY OF BARICITINIB AFTER INSUFFICIENT RESPONSE TO BDMARDS OR TSDMARDS IN PATIENTS WITH RA FROM JAPANESE MULTI-CENTER REGISTRY: 24-WEEK OUTCOMES}

H. Masahiro ${ }^{1}$, N. Takahashi ${ }^{2}$, T. Kojima ${ }^{3}$ on behalf of TBCR. ${ }^{1}$ Ichinomiya Municipal Hospital, Orthopedic Surgery / Rheumatology, Ichinomiya, Japan; ${ }^{2}$ Nagoya University Graduate School of Medicine, Orthopedic Surgery and Rheumatology, Nagoya, Japan; ${ }^{3}$ Nagoya University Graduate School of Medicine, Department of Orthopedic Surgery and Rheumatology, Nagoya, Japan

Background: EULAR has issued updated guidelines for the management of rheumatoid arthritis (RA) using conventional, biologic, and targeted synthetic DMARDs. In the 2019 update, the task force revised the preference of bDMARDs over tsDMARDs. In routine clinical practice, baricitinib is commonly used as second line or after. However, there is little information about the clinical efficacy and safety profile of baricitinib after failure of the previous agent, including another tsDMARD.

Objectives: The aim of this study was to evaluate the short-term effectiveness and safety profiles of baricitinib after insufficient response (IR) to bDMARDs or tsDMARDs in patients with RA in clinical settings.

Methods: RA patients who had been treated with baricitinib after failure of the previous agent were registered in the TBCR, a Japanese multicenter registry for RA patients treated with biologics or JAK inhibitors and followed for at least 24 weeks. Patients were divided into two groups according to the cause of failure of the previous treatment; IR ("After IR" group) and the others ("After non-IR" group). "After IR" group was further divided into four groups according to the previous agent; TNF inhibitor (TNFi group), IL-6 receptor inhibitor (IL-6Ri group), abatacept (ABT group) and tofacitinib (Tofa group). We assessed disease activities by CDAI score and drug retention rates between these groups. Furthermore, discontinuation rates due to IRs and adverse events (AEs) were evaluated. Results: A total of 86 consecutive RA patients were registered in this study. The previous treatment was as follows; TNF inhibitor: 38 (44.2\%), IL-6 receptor inhibitor: 23 (26.7\%), abatacept: 11 (12.8\%), tofacitinib: $13(15.1 \%)$ and the other: $1(1.2 \%)$. The cause of failure of the previous therapy were IRs ( $n=74: 86 \%)$, AEs: $(n=6: 7.0 \%)$ and the others ( $n=6: 7.0 \%)$. In "After IR" group, the most common

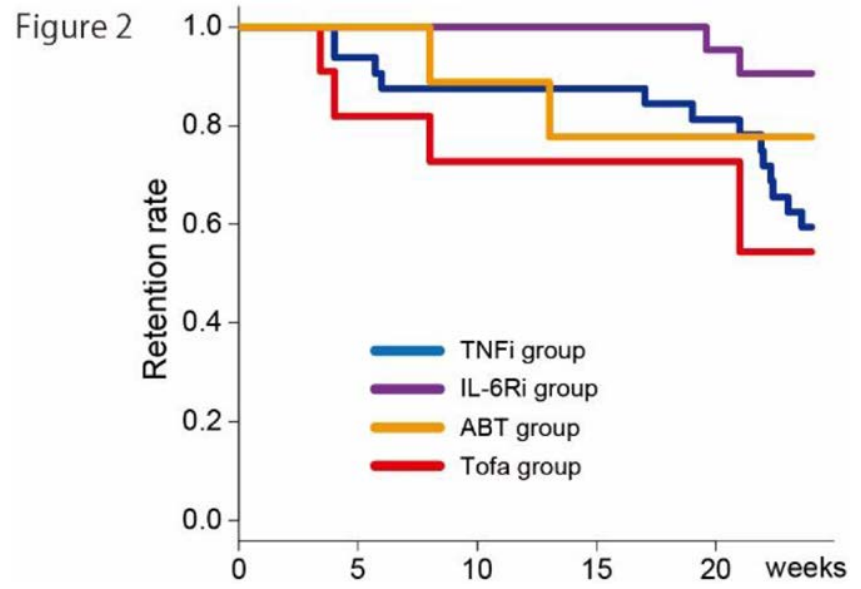

previous agents were TNFis (Table 1). While the percent change in CDAI was decreased at week 12 in all groups, those in Tofa group showed lower rates of improvement in CDAl compared to the others at week 24 (Figure 1). Drug retention rate at 24 -week was $59.4 \%$ in TNFi group, $90.5 \%$ in IL-6Ri group, $54.5 \%$ in ABT group and $77.8 \%$ in Tofa group (Figure 2). In the present study cohort, seven patients developed herpes zoster. All seven patients were treated with antiviral agents for herpes zoster and restarted baricitinib treatment (these cases were not treated as discontinuation due to AEs in this study). The overall Cumulative discontinuation rate due to IRs and AEs at 24 weeks were $9.7 \%$ and $7.3 \%$, respectively. 